\title{
Motivasi Penggunaan Layanan Internet Banking dan Hubungannya dengan Perbedaan Gender
}

\author{
Ellen Theresia Sihotang*, Larasati Ayu Sekarsari \\ Sekolah Tinggi Ilmu Ekonomi Perbanas, Surabaya \\ *ellen@perbanas.ac.id
}

\begin{abstract}
This study aims to describe and analyze the motivations of using internet banking with gender as the moderation to representation the consumer behavior which can provide design of marketing strategies based on customers' desires and needs. The sampling techniques are a purposive and a snowball sampling with 250 respondents in Surabaya. The result shows that perceived of usefulness, perceived ease of use, perceived of security and bank initiatives are motivations that encourage using the internet banking service. However, gender as the moderation does not influence to all these factors in using internet banking services.
\end{abstract}

Keywords: Consumer Behavior Gender, Internet Banking, Initiative Bank, Security, TAM.

\section{PENDAHULUAN}

Perkembangan teknologi membuat sektor perbankan melakukan berbagai inovasi terutama yang berkaitan dengan saluran distribusinya. Pengembangan saluran distribusi digital dikenal dengan electronic banking (E-Banking). Layanan perbankan yang termasuk kategori perbankan elektronik (E-Banking) antara lain Anjungan Tunai Mandiri (ATM), Short Message Service Banking (SMS Banking), Mobile Banking, Electronic Data Capture (EDC) dan Internet banking (Online Banking). Internet banking merupakan layanan yang memanfaatkan teknologi internet untuk melakukan transaksi perbankan melalui website bank (OJK, 2015).

Kehadiran layanan internet banking di Indonesia tidak terlepas dari semakin meningkatnya pengguna internet. Jumlah pengguna internet di Indonesia pada tahun 2016 adalah 132,7 juta orang dari total penduduk Indonesia yang berjumlah 256,2 juta orang. Meningkat 51,8\% jika dibandingkan dengan tahun 2014 yang masih berjumlah 88 juta pengguna. Mayoritas pengguna internet di Indonesia adalah pria sebesar $52,5 \%$ sedangkan wanita 47,5\% dari total pengguna internet. Sejumlah 84,2 juta atau $63,5 \%$ dari pengguna tersebut, telah melakukan transaksi online untuk pembayaran belanja online. Sebagian besar transaksi pembayaran masih dilakukan melalui ATM (36,7\%), sedangkan pembayaran melalui internet banking hanya sebesar 7,5\% atau 9,9 juta dari total pengguna internet (Asosiasi Penyelenggara Jasa Internet Indonesia, APJII, 2016). Hasil survey yang dilakukan oleh DI Marketing (Online Market Research In Asia) pada tahun 2017, mengungkapkan pengguna layanan internet banking di Indonesia mengalami peningkatan sebesar $34 \%$ dan didominasi oleh generasi muda. Penggunaan layanan tersebut lebih banyak untuk pembayaran 
belanja online. Berdasarkan pada hasil survey tersebut, layanan internet banking yang paling sering digunakan adalah Klik BCA. Hal tersebut sejalan dengan survey yang dilakukan oleh Frontier Consulting Group melalui konsep "Top Brand" dengan menggunakan pengukuran Top Brand Index (TBI) 2017. Klik BCA masih berada pada peringkat pertama dengan TBI 53,3\%.

Sejumlah penelitian terhadap layanan internet banking telah banyak dilakukan. Manfaat, komunikasi dan kenyamanan yang dirasakan merupakan faktor-faktor yang secara signifikan mempengaruhi penggunaan layanan internet banking (Ege Oruc \& Tatar 2017). Ahmed dan Phin (2016) mengungkapkan manfaat, kemudahan dan risiko yang dirasakan menjadi faktor-faktor penting penggunaan layanan internet banking. Norma subjektif, kemudahan dan keamanan juga merupakan faktor-faktor yang mempengaruhi penggunaan layanan internet banking (Chuchuen 2016). Norma subjektif, citra bank, inisiatif bank, kemampuan menggunakan internet banking, kegunaan penggunaan internet, kepercayaan, dan dukungan pemerintah merupakan faktorfaktor yang mempengaruhi penggunaan internet banking (Marakarkandy et al. 2017). Penelitian tersebut menguji inisiatif bank sebagai pengembangan dari penelitian sebelumnya. Artinya, ada keterlibatan pihak bank secara langsung terhadap pemasaran layanan internet banking dan menjadi hal yang menarik untuk diukur, karena keterlibatan bank mengacu pada apa yang menjadi kebutuhan dan keinginan pelanggan. Selain itu, penelitian tersebut menggunakan empat dimensi demografi yaitu gender, usia, pendapatan dan pendidikan sebagai moderasi. Selain usia, pendapatan dan pendidikan, penelitian tersebut juga mengungkapkan perbedaan gender terhadap faktor-faktor yang mendasari pelanggan atau nasabah menggunakan layanan internet banking. Berbagai hasil penelitian yang mengungkapkan faktor-faktor yang berpengaruh pada penggunaan layanan internet banking merupakan bagian dari upaya untuk proses pemahaman terhadap kebutuhan dan keinginan pelanggan. Proses tersebut membantu peneliti maupun praktisi memahami mengapa penerapan layanan internet banking belum dapat sejalan dengan perkembangannya (Shanmugam et al. 2015).

Berdasarkan hal tersebut maka penelitian ini bermaksud menggali motivasi yang mendorong penggunaan layanan internet banking dengan moderasi gender. Peran gender sebagai moderasi untuk mengetahui apakah gender mempengaruhi penggunaan layanan tersebut dan seperti apa perilakunya. Pemahaman terhadap keperilakuan tersebut dapat memberikan gambaran strategi pemasaran layanan internet banking yang tepat dalam rangka memenuhi kebutuhan dan keinginan pelanggan.

\section{Pemasaran Jasa}

Pengertian pemasaran secara singkat merupakan suatu proses menciptakan nilai pelanggan dan membangun hubungan yang kuat dengan pelanggan (Kotler \& Amstrong, 2016). Serangkaian proses tersebut diawali dengan pemahaman terhadap pasar berdasarkan pada apa yang menjadi kebutuhan dan keinginan pelanggan. Selanjutnya menetapkan pelanggan melalui strategi segmentasi, pasar sasaran dan posisinya, yang diintegrasikan kedalam program pemasaran dalam rangka menyampaikan nilai pelanggan yang superior melalui bauran pemasaran. Nilai pelanggan yang superior diartikan sebagai nilai yang lebih baik dari pesaing (Hawkins \& Mothersbaugh, 2013). Tahapan berikutnya adalah membangun hubungan dengan pelanggan yang pada akhirnya memperoleh imbalan dari pemberian nilai tersebut. Secara sederhana, proses pemasaran diawali dari pengenalan terhadap calon pelanggan dalam rangka mengetahui apa yang menjadi keinginan dan kebutuhannya. Mengetahui keinginan dan kebutuhan tersebut berdasarkan pada pemahaman terhadap perilaku konsumen. 


\section{Manfaat yang Dirasakan (Perceived Usefulness)}

Pemahaman keperilakuan konsumen terhadap penggunaan teknologi didasarkan pada model penerimaan teknologi (Technology Acceptance Model/TAM). TAM menghasilkan dua konstruk, yaitu manfaat yang dirasakan (perceived usefulness/PU) dan kemudahan yang dirasakan (perceived ease of use/PEOU). Keduanya memberikan pengaruh signifikan terhadap penggunaan teknologi (Davis, 1989).

Manfaat yang dirasakan (perceived usefulness) pada pemahaman penggunaan teknologi berkaitan dengan internet banking (online banking) merupakan kondisi dari seseorang yang merasakan bahwa internet banking sebagai suatu sistem memiliki fungsi sehingga seseorang cenderung untuk menggunakannya (Chandio et al. 2017). Pengertian tersebut berdasarkan pada pemahaman konstruk yang sesungguhnya bahwa manfaat yang dirasakan diartikan sebagai hasil dari keputusan seseorang yang meyakini bahwa dengan penggunaan teknologi akan membantu menyelesaikan pekerjaan dengan lebih baik (Venkatesh \& Bala 2008; Davis 1989). Salah satu manfaat yang dirasakan adalah adanya penghematan waktu bertransaksi tanpa harus datang ke bank (Sihotang 2016). Penelitian sebelumnya juga mengungkapkan bahwa manfaat yang dirasakan (perceived usefulness) berpengaruh secara positif terhadap keputusan menggunakan layanan internet banking. (Marakarkandy et al. 2017; Ahmed \& Phin 2016; Maditinos et al. 2013; Yousafzai \& Yani-de-Soriano 2012). Penelitian lainnya dengan konstruk yang sama pada penggunaan mobile banking, menyatakan bahwa manfaat yang dirasakan berpengaruh positif terhadap penggunaan layanan tersebut (Alalwan et al. 2016: Riquelme \& Rios 2010).

Dari penelitian sebelumnya, faktorfaktor yang mempengaruhi keputusan menggunakan layanan internet banking dengan moderasi gender mengungkapkan adanya perbedaan keperilakuan. Penggunaan internet banking pada pria secara signifikan dipengaruhi oleh adanya manfaat dari layanan tersebut (Marakarkandy et al. 2017; Riquelme \& Rios 2010). Hasil tersebut sesuai dengan konstruk dasar dari penelitian sebelumnya yang mengungkapkan bahwa perilaku penggunaan teknologi pada pria lebih kuat dipengaruhi oleh manfaat yang dirasakan dibandingkan dengan wanita (Venkatesh \& Morris 2000)

\section{Kemudahan Penggunaan yang Dirasakan (Perceived Ease of Use)}

Konstruk berupa kemudahan penggunaan yang dirasakan (perceived ease of use) merupakan tingkatan yang memberikan keyakinan kepada seseorang bahwa dengan menggunakan sistem tertentu akan terbebas dari segala bentuk kesulitan (Davis 1989). Pekerjaan dapat terselesaikan dengan segera dan mempermudah prosesnya. Selain keyakinan terhadap manfaat yang diperoleh, seseorang yang menggunakan teknologi, pada saat bersamaan dapat merasakan suatu sistem tersebut terlalu sulit atau mudah untuk digunakan. Artinya, manfaat yang dirasakan dengan kemudahan dari penggunaan teknologi sebanding sehingga keduanya menjadi konstruk yang tidak terpisahkan dari penggunaan teknologi. Kemudahan yang dirasakan berpengaruh secara positif terhadap penggunaan layanan internet banking (Marakarkandy et al. 2017). Penerapan faktor kemudahan penggunaan yang dirasakan pada objek penelitian mobile banking menyatakan bahwa kemudahan yang dirasakan berpengaruh secara positif terhadap penggunaan layanan tersebut (Chuchuen 2016; Alalwan et al. 2016; Yiu et al. 2007).

Pengembangan konstruk TAM pada beberapa penelitian berikutnya adalah menguji komponen demografi, salah satunya gender. Layanan internet banking lebih banyak digunakan oleh pria dibandingkan dengan wanita (Serener 2016). Perbedaan gender berperan penting terhadap penerimaan serta penggunaan teknologi. Penggunaan layanan internet banking pada wanita secara signifikan lebih kuat dipengaruhi oleh adanya kemudahan 
penggunaan dari layanan tersebut. Motivasi wanita menggunakan layanan internet banking secara signifikan dipengaruhi oleh adanya kemudahan penggunaan (Marakarkandy et al. 2017; Yousafzai \& Yani-de-Soriano 2012; Riquelme \& Rios 2010). Hasil tersebut sejalan dengan penelitian yang dilakukan oleh Venkatesh dan Morris (2000), yang mengembangkan konsep TAM dengan moderasi Gender mengungkapkan pria lebih berfokus pada manfaat penggunaan teknologi sedangkan wanita lebih kepada kemudahan dan norma subjektif yang lebih banyak dipengaruhi oleh berbagai pendapat orang lain selain keputusan dari dirinya sendiri.

\section{Keamanan yang Dirasakan (Perceived Security)}

Keamanan merupakan salah satu faktor kunci yang dapat mengubah persepsi pelanggan terhadap penggunaan layanan online banking. Persepsi pelanggan potensial terhadap keamanan teknologi tersebut adalah tidak terjadi kekeliruan atau kesalahan teknis pada saat penyelesaian transaksi perbankan (Massilamany \& Nadarajan 2017). Keamanan diartikan tidak ada kecurangan atau gangguan akses terhadap rekening pengguna layanan internet banking (Clemes et al. 2012). Penelitian kualitatif terhadap pengguna layanan internet banking di United Kingdom (UK) mengungkapkan bahwa keamanan sebagai faktor terpenting yang mempengaruhi penggunaan layanan tersebut (Shanmugam et al. 2015). Hasil penelitian kuantitatif menyatakan bahwa keamanan merupakan faktor penentu utama yang mempengaruhi penggunaan layanan internet banking (Sihotang 2016). Penelitian pada layanan mobile banking menyatakan bahwa keamanan bertransaksi menjadi perhatian khusus di era mobile saat ini (Tseng et al. 2017). Penelitian empiris secara khusus menguji keamanan dari website layanan online (internet) banking, menyatakan bahwa keamanan website berpengaruh positif signifikan terhadap penggunaan layanan internet banking (Chandio et al. 2017). Faktor keamanan yang dirasakan berkaitan dengan transaksi perbankan berpengaruh secara positif terhadap penggunaan layanan internet banking (Massilamany \& Nadarajan 2017; Mukhtar 2015; Susanto et al. 2013). Penelitian terhadap layanan mobile banking juga mengungkapkan hal yang sama terhadap keamanan transaksi perbankan (Maditinos et al. 2013).

Keamanan terhadap penggunaan layanan teknologi perbankan dengan moderasi Gender relevan terhadap pria maupun wanita (Riquelme \& Rios 2010) sedangkan Marakarkandy et al. 2017 menyatakan lebih kuat mempengaruhi wanita, tidak signifikan terhadap pria.

\section{Inisiatif Bank}

Inisiatif bank merupakan upaya bank dalam rangka mempromosikan dan mendukung keberadaan layanan internet banking sebagai saluran distribusi digital. Faktor tersebut sebagai variabel terbaru dari penelitian dilakukan oleh Marakarkandy et al. 2017. Keterlibatan bank dengan menciptakan kesadaran bagi pelanggan bahwa bertransaksi melalui internet banking berbeda ketika bertransaksi ke bank. Memperbarui web site dengan informasi terbaru serta membuat situs web mudah dimengerti mempengaruhi penggunaan layanan internet banking.

Faktor inisiatif bank berpengaruh secara positif terhadap penggunaan layanan internet banking. Hasil dari moderasi gender, pria lebih kuat dipengaruhi oleh inisiatif bank dibandingkan dengan wanita (Marakarkandy et al. 2017). 
Kerangka Konsep Penelitian

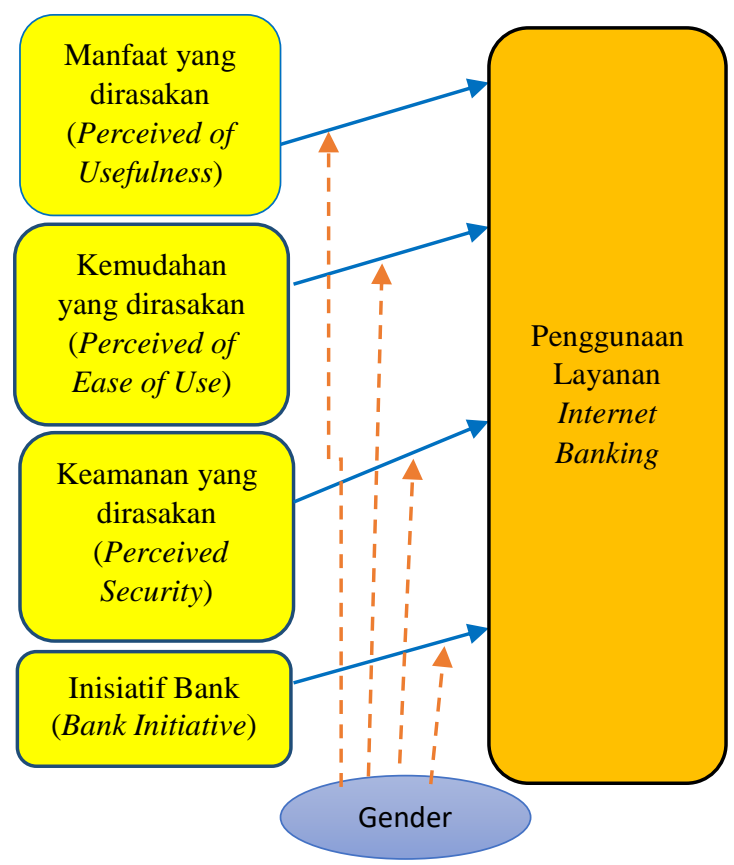

Gambar 1. Kerangka Konseptual Sumber: Kajian Penelitian Terdahulu

\section{Hipotesis}

Berdasarkan pada beberapa penelitian sebelumnya maka hipotesis pada penelitian ini adalah sebagai berikut:

$\begin{array}{llrr}\text { H1.a : } & \text { Manfaat } & \text { yang } & \text { dirasakan } \\ & \text { berpengaruh } & \text { positif } & \text { terhadap } \\ \text { penggunaan } & \text { layanan } & \text { internet } \\ & \text { banking. }\end{array}$

H1.b : Pria lebih kuat dipengaruhi oleh manfaat yang dirasakan dari penggunaan layanan internet banking dibandingkan wanita

H2.a : $\begin{array}{llr}\text { Kemudahan yang dirasakan } \\ \text { berpengaruh } \\ \text { penggunaan } \\ \text { banking }\end{array}$

H2.b : Wanita lebih kuat dipengaruhi oleh kemudahan yang dirasakan terhadap penggunaan layanan internet banking dibandingkan dengan pria.

H3.a : Keamanan berpengaruh positif terhadap penggunaan layanan internet banking

H3.b : Pria dan wanita dipengaruhi oleh faktor keamanan terhadap penggunaan layanan internet banking.

H4.a : Inisiatif bank berpengaruh secara positif terhadap penggunaan layanan internet banking.

H4.b : Pria lebih kuat dipengaruhi oleh inisiatif bank terhadap penggunaan layanan internet banking dibandingkan wanita.

\section{METODE}

Penelitian ini merupakan penelitian eksplanatori dengan metode kuantitatif. Studi awal dilakukan melalui kelompok diskusi fokus dengan tujuan untuk memperoleh data awal terkait dengan penggunaan layanan internet banking. Pengalaman responden kelompok diskusi fokus, sebagai dasar merancang dan menyesuaikan dengan pertanyaan-pertanyaan instrumen dari penelitian sebelumnya. Populasi pada penelitian ini adalah pengguna layanan internet banking bank konvensional maupun syariah di wilayah kota Surabaya. Teknik pengambilan sampel yang digunakan adalah kombinasi purposive dan snowball sampling, dengan demikian ada kesempatan bagi responden lainnya untuk memberikan rekomendasi pengguna internet banking kepada peneliti. Purposive sampling dengan sampel non probabilitas memiliki kriteria, sebagai berikut:

a) responden merupakan nasabah individu dari simpanan maupun pinjaman

b) minimal telah menggunakan layanan internet banking selama 1 tahun

c) rentang usia adalah 17-60 tahun.

Batas usia minimal 17 tahun, dianggap telah memiliki kartu identitas sebagai salah satu syarat utama pembukaan rekening bank. Usia maksimal 60 tahun diasumsikan belum memasuki masa pensiun. Pengumpulan data dilakukan melalui instrumen yang disebar secara manual. Penelitian ini menggunakan perangkat lunak Statistical Package for the Social Science (SPSS) versi 23 untuk pengolahan data deskriptif dan penggujian instrumen sampel kecil dengan jumlah responden 65 orang. Warp Partial Least Squares (Warp PLS) versi 6,0 digunakan 
untuk penggujian sampel besar 250 responden.

Face validity merupakan tahapan awal uji validitas instrumen. Selanjutnya dilakukan penggujian sampel kecil. Hasil uji validitas instrumen dengan KMO dan Bartlett pada item-item variabel manfaat, kemudahan, keamanan yang dirasakan, inisiatif bank dan penggunaan layanan internet banking bernilai 0,741. Artinya, instrumen dengan sejumlah variabel tersebut dapat dilanjutkan untuk dilakukan analisis faktor konfirmatori yang bisa dilihat pada tabel 1 .

Tabel 1. Hasil Uji Validitas Sampel Kecil

\begin{tabular}{lcc}
\hline \multicolumn{1}{c}{ Variabel } & KMO & Bartlett's \\
\hline Manfaat & & \\
Kemudahan & & \\
Keamanan & 0,741 & 0,000 \\
Inisiatif Bank & & \\
Penggunaan Layanan & & \\
Internet Banking & & \\
Sumber: Hasil Pengolahan Data Primer, 2018
\end{tabular}

Hasil uji validitas dengan Analisis Faktor Konfirmatori (Confirmatory Factor Analysis/CFA), terdapat beberapa item variabel-variabel yang memiliki nilai faktor loading kurang dari 0,4 sehingga dinyatakan tidak valid. Hair et al (2010:117) menjelaskan faktor loading 0,30-0,40 merupakan nilai minimal pemenuhan dari faktor loading. Hasil dari analisis faktor konfirmatori pada sampel kecil terdapat 32 item pertanyaan yang valid dari jumlah total 60 .

Untuk uji reliabilitas instrumen menggunakan uji statistik Cronbach's Alpha. Pemenuhan nilai reliabel instrumen dengan Cronbach's Alpha minimum 0,70 dan 0,60 untuk penelitian eksploratori (Hair et al, 2010:124). Hasil uji reliabilitas variabelvariabel pada penelitian ini telah memenuhi persyaratan nilai Cronbach's Alpha lebih dari 0,70 yang bisa dilihat pada tabel 2 .

Tabel 2. Hasil Uji Reliabilitas

\begin{tabular}{lcc}
\hline \multicolumn{1}{c}{ Variabel } & $\begin{array}{c}\text { Cronbach's } \\
\text { Alpha }\end{array}$ & Keterangan \\
\hline Manfaat & 0,868 & Reliabel \\
Kemudahan & 0,903 & Reliabel \\
Keamanan & 0,848 & Reliabel \\
\hline
\end{tabular}

\begin{tabular}{lcc}
\hline \multicolumn{1}{c}{ Variabel } & $\begin{array}{c}\text { Cronbach's } \\
\text { Alpha }\end{array}$ & Keterangan \\
\hline Inisiatif Bank & 0,879 & Reliabel \\
Penggunaan & 0,938 & Reliabel \\
Internet Banking & & \\
\hline
\end{tabular}

Sumber: Hasil Pengolahan Data Primer, 2018

Berdasarkan pada uji validitas dengan menggunakan Analisis Faktor Konfirmatori (CFA) dan uji reliabilitas Cronbach's Alpha maka instrumen pada penelitian ini telah layak digunakan.

\section{HASIL DAN PEMBAHASAN}

Profil demografi 250 responden sebagian besar berjenis kelamin wanita, berjumlah 150 orang (60\%). Jenis kelamin pria sejumlah 100 orang $(40 \%)$. Usia responden mayoritas pada rentang 17-25 tahun, berjumlah 105 orang (42\%). Berdasarkan angka tersebut, kategori responden pada penelitian ini adalah usia produktif dan generasi muda. Tingkat pendidikan yang telah terselesaikan oleh 250 responden, mayoritas adalah lulusan Sarjana (Strata Satu) sejumlah 123 orang $(49,2 \%)$. Artinya responden pada penelitian ini termasuk kategori yang berpendidikan. Pekerjaan dari sejumlah responden mayoritas adalah sebagai staff/pegawai (40\%) berjumlah 100 orang. Rata-rata tingkat penghasilan utama setiap bulannya pada rentang nominal Rp 3-6 juta berjumlah 109 orang (43,6\%). Rincian karakteristik demografi responden pada penelitian ini tercantum pada tabel 3 .

Tabel 3. Karakteristik Demografi Responden

\begin{tabular}{lrr}
\hline Keterangan & Frekuensi & Persentase \\
\hline Usia & & \\
17-25 tahun & 105 & $42,0 \%$ \\
26-35 tahun & 91 & $36,4 \%$ \\
$36-45$ tahun & 27 & $10,8 \%$ \\
$46-55$ tahun & 26 & $10,4 \%$ \\
$>55$ tahun & 1 & $0,4 \%$ \\
\hline Pendidikan & & \\
SMU & 62 & $24,8 \%$ \\
Diploma & 7 & $2,8 \%$ \\
Sarjana (S1) & 123 & $49,2 \%$ \\
Pasca & 58 & $23,2 \%$ \\
(S2/S3) & & \\
\hline Pekerjaan & & \\
Pelajar & 68 & $27,2 \%$ \\
Pegawai/Staff & 100 & $40,0 \%$ \\
Manajer/Supervisor & 15 & $6,0 \%$ \\
/Direktur & & \\
\hline
\end{tabular}




\begin{tabular}{lrr}
\hline Keterangan & Frekuensi & Persentase \\
\hline Wiraswasta & 15 & $6,0 \%$ \\
Profesional & 52 & $20,8 \%$ \\
\hline Penghasilan & & \\
<Rp 3 juta & 66 & $26,4 \%$ \\
Rp 3-6 juta & 109 & $43,6 \%$ \\
Rp 6-9 juta & 45 & $18,0 \%$ \\
Rp 9-11 juta & 11 & $4,4 \%$ \\
>Rp 11 juta & 19 & $7,6 \%$ \\
\hline \multicolumn{2}{l}{ Sumber: Hasil Pengolahan Data Primer, 2018 }
\end{tabular}

Sejumlah 165 orang (66\%) hanya menggunakan satu layanan internet banking. Fitur layanan internet banking yang paling sering diakses adalah cek saldo dan pengiriman uang atau transfer. Sejumlah 140 orang $(56 \%)$ menggunakan telepon pintar sebagai media untuk akses fitur-fitur tersebut. Mayoritas telah menggunakan layanan tersebut selama 5 tahun. Klik BCA merupakan internet banking yang paling banyak digunakan oleh 132 responden $(52,8 \%)$.

Pengukuran outer dan iner model menggunakan Warp PLS 6.0. Perangkat lunak tersebut digunakan pada penggujian sampel besar karena dapat sekaligus menguji variabel gender sebagai moderasi pada motivasi penggunaan layanan internet banking.

Pengukuran outer model berkaitan dengan uji validitas dan reabilitas konstruk. Hair et al (2017:144) menjelaskan indikator dengan outer loading antara 0,40 dan 0,70 masih dapat dipertimbangkan, penghapusan dapat dilakukan untuk meningkatkan reliabilitas komposit dan AVE diatas nilai yang disyaratkan. Kisaran angka tersebut menjadi kriteria faktor loading yang digunakan pada uji validitas konvergen.

Uji validitas konvergen (tabel 4) menunjukkan bahwa item-item pertanyaan dari variabel manfaat yang dirasakan (Perceived of Usefulness/PU) memenuhi syarat valid berjumlah 8 dari 16 item, yaitu PU1, PU2, PU3, PU4, PU6, PU7, PU8 dan PU12. Faktor loading tertinggi pada item PU6 $(0,808)$, dengan pernyataan manfaat internet banking salah satunya dapat diakses kapan pun bahkan pada hari libur. Artinya manfaat yang paling dirasakan adalah tidak adanya pembatasan waktu terhadap penggunaan internet banking.
Item-item dari variabel kemudahan yang dirasakan (Perceived Ease of Use/PEU) berjumlah 9 dan semuanya memenuhi syarat valid. Item pertanyaan dengan faktor loading tertinggi senilai 0,811 pada PEU18. Berkaitan dengan kemudahan penggunaan hal yang terpenting adalah internet banking mudah dipahami tahapan-tahapan penggunaannya.

Variabel keamanan (Perceived of Security/PS) yang valid berjumlah 8 dari 11 item pertanyaan, terdiri dari PS26, PS27, PS28, PS30, PS33, PS34, PS35, PS36. Nilai faktor loading tertinggi dari keamanan ada pada item PS27 (0,850). Pernyataannya adalah bahwa proses transaksi keuangan melalui layanan internet banking aman. Keamanan pada proses transaksi keuangan menjadi yang terpenting

Item-item pertanyaan inisiatif bank (IB) yang berjumlah 5 semuanya memenuhi kriteria valid. Faktor loading tertinggi pada angka 0,869 . Pernyataan inisiatif bank terkait dengan tersedianya fitur-fitur internet banking secara lengkap selain keterlibatan bank memberikan informasi internet banking.

Variabel penggunaan internet banking (PIB) yang berjumlah 12, semuanya telah memenuhi syarat valid. Secara keseluruhan jumlah item pertanyaan instumen yang valid adalah 42. Hasil penggujian tersebut tercantum pada tabel 4 .

Tabel 4 Validitas Konvergen

\begin{tabular}{|c|c|c|c|c|c|}
\hline \multirow{2}{*}{$\begin{array}{l}\text { Item- } \\
\text { item }\end{array}$} & \multicolumn{5}{|c|}{ Komponen } \\
\hline & $\overline{\mathrm{PU}}$ & PEU & PS & IB & PIB \\
\hline PU1 & 0,771 & & & & \\
\hline PU2 & 0,750 & & & & \\
\hline PU3 & 0,740 & & & & \\
\hline PU4 & 0.612 & & & & \\
\hline PU6 & 0,808 & & & & \\
\hline PU7 & 0,724 & & & & \\
\hline PU8 & 0,754 & & & & \\
\hline PU12 & 0,578 & & & & \\
\hline PEU17 & & 0,764 & & & \\
\hline PEU18 & & 0,811 & & & \\
\hline PEU19 & & 0,784 & & & \\
\hline PEU20 & & 0,772 & & & \\
\hline PEU21 & & 0,786 & & & \\
\hline PEU22 & & 0,769 & & & \\
\hline PEU23 & & 0,655 & & & \\
\hline PEU24 & & 0,618 & & & \\
\hline PEU25 & & 0,607 & & & \\
\hline PS26 & & & 0,83 & & \\
\hline
\end{tabular}




\begin{tabular}{|c|c|c|c|c|c|}
\hline \multirow{2}{*}{$\begin{array}{l}\text { Item- } \\
\text { item }\end{array}$} & \multicolumn{5}{|c|}{ Komponen } \\
\hline & $\mathrm{PU}$ & PEU & PS & IB & PIB \\
\hline PS27 & & & 0,850 & & \\
\hline PS28 & & & 0,787 & & \\
\hline PS30 & & & 0,795 & & \\
\hline PS33 & & & 0,687 & & \\
\hline PS34 & & & 0,839 & & \\
\hline PS35 & & & 0,744 & & \\
\hline PS36 & & & 0,818 & & \\
\hline IB44 & & & & 0,788 & \\
\hline IB 45 & & & & 0,837 & \\
\hline IB46 & & & & 0,869 & \\
\hline IB47 & & & & 0,844 & \\
\hline IB48 & & & & 0,863 & \\
\hline PIB49 & & & & & 0,743 \\
\hline PIB50 & & & & & 0,737 \\
\hline PIB51 & & & & & 0,821 \\
\hline PIB52 & & & & & 0,790 \\
\hline PIB53 & & & & & 0,730 \\
\hline PIB54 & & & & & 0,747 \\
\hline PIB55 & & & & & 0,877 \\
\hline PIB56 & & & & & 0,712 \\
\hline PIB57 & & & & & 0,788 \\
\hline PIB58 & & & & & 0,800 \\
\hline PIB59 & & & & & 0,727 \\
\hline PIB60 & & & & & 0,766 \\
\hline
\end{tabular}

Sumber: Hasil Pengolahan Data Primer, 2018

Penggujian validitas diskriminan dengan melihat nilai Average Variance Extracted (AVE). Hair et al (2017: 144) mensyaratkan nilai minimal AVE sebaiknya lebih besar dari 0,50. Syarat reliabilitas konstruk dengan Cronbach's Alpha adalah lebih besar dari 0,70 (Hair et al, 2017:144). Berdasarkan pada tabel 5, nilai $A V E$ \& Cronbach's Alpha, masing-masing variabel memiliki angka lebih besar dari yang disyaratkan sehingga secara keseluruhan konstruk telah memenuhi syarat dan dapat dilanjutkan pada pengukuran model struktural (inner model).

Tabel 5. Nilai AVE \& Cronbach's Alpha

\begin{tabular}{lcc}
\hline \multicolumn{1}{c}{ Variabel } & $\begin{array}{c}\text { Nilai } \\
\text { AVE }\end{array}$ & $\begin{array}{c}\text { Cronbach's } \\
\text { Alpha }\end{array}$ \\
\hline Manfaat (PU) & 0,52 & 0,87 \\
$\begin{array}{l}\text { Kemudahan } \\
\text { (PEU) }\end{array}$ & 0,54 & 0,89 \\
$\begin{array}{l}\text { Keamanan (PS) } \\
\text { Inisiatif Bank (IB) }\end{array}$ & 0,64 & 0,92 \\
$\begin{array}{l}\text { Penggunaan } \\
\text { Internet } \\
\text { Banking (PIB) }\end{array}$ & 0,60 & 0,90 \\
Sumber & & 0,94
\end{tabular}

Sumber: Hasil Pengolahan Data Primer, 2018

Pengukuran model struktur moderasi diawali dari nilai kolineralitas dengan syarat indikator Average full collinearity VIF
(AFVIF) dibawah batasan nilai 5 (Hair et al, 2017:170). Penggujian model moderasi (tabel 6) dengan indikator AFVIF bernilai 1,92 sehingga dapat dikatakan telah memenuhi syarat interaksi antarvariabel atau tidak terjadi multikolineritas (Kock 2013)

Indikator model fit juga telah terpenuhi dengan nilai Average path coefficient (APC) dan Average $R$-squared (ARS) signifikan dengan nilai $\mathrm{p}$ kurang dari 0.001. Nilai $R$ square $\left(\mathrm{R}^{2}\right)$ sebesar 0,52 . Artinya variabilitas konstruk penggunaan layanan internet banking yang dapat dijelaskan oleh konstruk manfaat, kemudahan keamanan yang dirasakan serta inisiatif bank sebesar 52\%. Secara rinci hasil pengukuran kesesuain model (Model Fit) tercantum pada tabel 6 berikut ini :

Tabel 6. Hasil Kesesuain Model (Model Fit)

\begin{tabular}{lc}
\hline Indikator & Nilai \\
\hline AFVIF & 1,92 \\
APC & 0,$13 ; \mathrm{p}=0,009$ \\
$\mathrm{R}^{2}$ & 0,52 \\
\hline
\end{tabular}

Sumber: Hasil Pengolahan Data Primer, 2018

Hair et al (2017:206) menjelaskan tingkat signifikansi pada nilai 5\% maka nilai $\mathrm{p}$ lebih kecil dari 0,05 untuk dapat memberikan kesimpulan bahwa hubungan yang dipertimbangkan signifikan pada tingkat 5\%. Pengukuran model struktur juga sebagai penggujian terhadap sejumlah hipotesis pada penelitian ini bisa dilihat pada tabel 7.

Tabel 7. Hasil Pengujian Hipotesis

\begin{tabular}{|c|c|c|c|c|}
\hline $\begin{array}{l}\text { Hipo } \\
\text { tesis }\end{array}$ & Hubungan & $\begin{array}{l}\text { Koef } \\
\text { Jalur }\end{array}$ & $\begin{array}{c}\text { Nilai } \\
\mathrm{p}\end{array}$ & Ket \\
\hline H1.a & Manfaat $\rightarrow$ PIB & 0,27 & 0,001 & Sig \\
\hline H1.b & $\begin{array}{l}\text { Manfaat--- } \\
\text { Gender---PIB }\end{array}$ & 0,02 & 0,35 & $\begin{array}{c}\text { Tidak } \\
\text { Sig }\end{array}$ \\
\hline $\mathrm{H} 2 . \mathrm{a}$ & $\begin{array}{l}\text { Kemudahan } \rightarrow \\
\text { PIB }\end{array}$ & 0,12 & 0,02 & Sig \\
\hline $\mathrm{H} 2 . \mathrm{b}$ & $\begin{array}{l}\text { Kemudahan--- } \\
\text { Gender---PIB }\end{array}$ & $-0,07$ & 0,14 & $\begin{array}{c}\text { Tidak } \\
\text { Sig }\end{array}$ \\
\hline H3.a & $\begin{array}{l}\text { Keamanan } \rightarrow \\
\text { PIB }\end{array}$ & 0,25 & 0,001 & Sig \\
\hline H3.b & $\begin{array}{l}\text { Keamanan--- } \\
\text { Gender---PIB }\end{array}$ & 0,04 & 0,26 & $\begin{array}{c}\text { Tidak } \\
\text { Sig }\end{array}$ \\
\hline H4.a & $\begin{array}{l}\text { Inisiatif } \\
\text { Bank } \rightarrow \text { PIB }\end{array}$ & 0,25 & 0,001 & Sig \\
\hline H4.b & $\begin{array}{l}\text { Inisiatif Bank-- } \\
\text { Gender---PIB }\end{array}$ & $-0,001$ & 0,5 & $\begin{array}{c}\text { Tidak } \\
\text { Sig }\end{array}$ \\
\hline
\end{tabular}

Sumber: Hasil Pengolahan Data Primer, 2018 
Estimasi koefisien jalur manfaat yang dirasakan terhadap penggunaan layanan internet banking senilai 0,27 dan signifikan pada nilai $\mathrm{p}$ kurang dari 0,001. Berarti manfaat yang dirasakan berpengaruh positif terhadap penggunaan layanan internet banking dengan demikian hipotesis H1.a. dapat diterima. Hasil ini juga sejalan dengan hasil penelitian yang dilakukan oleh Marakarkandy et al. 2017. Moderasi koefisien gender pada manfaat yang dirasakan terhadap penggunaan layanan internet banking senilai 0,02 dan tidak signifikan pada nilai $\mathrm{p}$ sebesar 0,35 . Artinya manfaat yang dirasakan terhadap penggunaan layanan internet banking yang dimoderasi oleh gender tidak memiliki pengaruh, dengan demikian hipotesis H1.b. ditolak.

Konstruk kemudahan yang dirasakan terhadap penggunaan layanan internet banking memiliki koefisien nilai 0,12 dan signifikan pada nilai p kurang dari 0,02. Berarti kemudahan yang dirasakan berpengaruh positif terhadap penggunaan layanan internet banking, dengan demikian hipotesis H2.a dapat diterima. Koefisien Gender pada kemudahan yang dirasakan terhadap penggunaan layanan internet banking bernilai $-0,07$ dan tidak signifikan pada nilai $\mathrm{p}$ sebesar 0,14 sehingga hipotesis H2.b ditolak karena konstruk kemudahan yang dirasakan terhadap penggunaan layanan internet banking dengan moderasi gender tidak memiliki pengaruh.

Keamanan terhadap penggunaan internet banking memiliki nilai koefisien 0,25 signifikan pada nilai $\mathrm{p}$ kurang dari 0,001. Konstruk keamanan berarti berpengaruh positif terhadap penggunaan layanan internet banking, dengan demikian hipotesis H3.a dapat diterima. Moderasi Gender terhadap keamanan memiliki koefisien senilai 0,04 dan tidak signifikan pada nilai $\mathrm{p}$ lebih dari 0,05 dengan angka 0,26. Konstruk keamanan terhadap penggunaan layanan internet banking dengan moderasi gender tidak memiliki pengaruh sehingga hipotesis H3.b ditolak. Hasil tersebut sama dengan pernyataan dari hasil penelitian Riquelme \& Rios (2010)

Inisiatif bank memiliki koefisien nilai 0,25 dan signifikan pada nilai $\mathrm{p}$ kurang dari 0,001. Artinya konstruk tersebut berpengaruh positif terhadap penggunaan layanan internet banking sehingga hipotesis H4.a dapat diterima. Koefisien gender pada variabel inisiatif bank terhadap penggunaan layanan internet banking senilai -0,001 dan tidak signifikan pada nilai p sebesar 0,50. Konstruk inisiatif bank terhadap penggunaan layanan internet banking dengan moderasi Gender tidak memiliki pengaruh, dengan demikian H4.b ditolak.

Hasil pengukuran model struktur secara rinci tercantum pada Gambar 2. merupakan hasil estimasi model penggunaan layanan internet banking dengan moderasi gender.

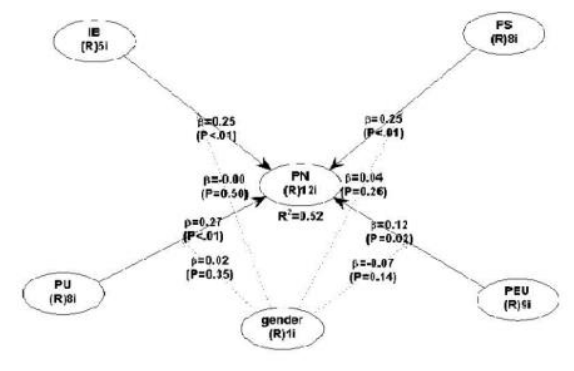

Gambar 2. Hasil Estimasi Model Penggunaan

Layanan Internet Banking dengan Moderasi Gender

Sumber: Hasil Pengolahan Data Primer, 2018

\section{Kesimpulan}

Layanan internet banking di wilayah kota Surabaya sebagian besar digunakan oleh golongan berusia muda dan telah menyelesaikan pendidikan perguruan tinggi. Sebagian besar bekerja sebagai pegawai atau karyawan swasta maupun instansi pemerintahan. Telah menggunakan layanan internet banking selama kurang lebih 5 tahun dan hanya menggunakan satu internet banking dari bank tertentu. Cek saldo dan pengiriman uang merupakan fitur yang paling sering diakses menggunakan telepon pintar (smartphone). 
Motivasi penggunaan layanan internet banking dipengaruhi oleh faktor-faktor manfaat, kemudahan penggunaan, dan keamanan dalam bertransaksi serta inisiatif bank.

Moderasi gender terhadap motivasi penggunaan layanan internet banking tidak memiliki pengaruh. Motivasi tersebut berlaku bagi pria maupun wanita.

Strategi pemasaran layanan internet banking di kota Surabaya, pada generasi muda yang sudah cukup lama menggunakan layanan internet banking tidak berdasarkan pada gender, namun lebih memperhatikan faktor-faktor manfaat yang dapat diakses setiap waktu. Faktor kemudahan penggunaan lebih memperhatikan pada tahapan-tahapan penggunaan yang mudah dipahami. Proses transaksi keuangan yang aman menjadi salah satu pertimbangan penggunaan internet banking. Inisiatif bank dengan menyediakan fitur-fitur transaksi secara lengkap, dimana semua informasi berbagai transaksi perbankan dapat dilakukan melalui internet banking akan mendorong pelanggan menggunakan internet banking. Hal ini sekaligus diharapkan dapat meningkatkan volume transaksi perbankan secara beragam melalui layanan internet banking.

\section{DAFTAR PUSTAKA}

Ahmed, E.M. and Phin, G.S., 2016. Factors Influencing the Adoption of Internet Banking in Malaysia. Journal of Internet Banking and Commerce, 21(1), p.1.

Alalwan, Ali Abdallah, et al. "Consumer Adoption of Mobile Banking in Jordan: Examining the Role of Usefulness, Ease of use, Perceived Risk and SelfEfficacy." Journal of Enterprise Information Management 29.1 (2016): 118-139.

Asosiasi Penyelenggara Jasa Internet Indonesia., Profile Pengguna Internet Indonesia 2016, diunduh tanggal 27 April 2017, dari https://apjii.or.id/ survei2017/kirimlink

Chandio, F.H., Irani, Z., Zeki, A.M., Shah, A. and Shah, S.C., 2017. Online Banking Information Systems
Acceptance: An Empirical Examination of System Characteristics and Web Security. Information Systems Management.

Chuchuen, C., 2016. The Perception of Mobile Banking Adoption: The Study of Behavioral, Security, and Trust in Thailand. International Journal of Social Science and Humanity, 6(7), p.547.

Clemes, M.D., Gan, C. and Du, J., 2012. The Factors Impacting on Customers' Decisions to Adopt Internet Banking. Banks and bank systems, 7(3), pp.33-50.

Davis, F.D., 1989. Perceived Usefulness, Perceived Ease of Use, and User Acceptance of Information Technology. MIS quarterly, pp.319-340.

DI Marketing Online Market Research In Asia., (2017). Banking Service Usage in Indonesia, diunduh tanggal 25 Mei 2017 dari ttps://www.di-onlinesurvey.com/en/ 2017/04/21/banking-service-usage-inindonesia/

Hair, Joseph F., G. Tomas M. Hult., Christian M. Ringle., Marko Sarstedt. (2017). A Primer On Partial Least Squares Structural Equation Modeling (PLS-SEM). Los Angeles: Sage.

Hair, Joseph F., William C. Black., Barry J.Babin., Rolph E.Anderson., Ronald L. Tatham. (2010). Multivariate Data Analysis, $7^{\text {th }}$ ed, Upper Saddle River: Pearson Prentice Hall, Inc.

Hawkins, D. I. and D.L. Mathersbaugh., (2013). Consumer Behavior: Building Marketing Strategy, $12^{\text {th }}$ ed, New York: McGraw-Hill Companies, Inc.

Kock, Ned., (2013). Using WarpPLS in Ecollaboration Studies: What If I Have Only One Group and One Condition? International Journal of $e$ Collaboration, 9(3), pp. 1-12.

Kotler, P \& Gary, A., (2016). Principles of Marketing Global, Global Edition, $16^{\text {th }}$ ed, Upper Saddle River: Pearson Education Limited.

Maditinos, D., Chatzoudes, D. and Sarigiannidis, L., 2013. An Examination of the Critical Factors Affecting 
Consumer Acceptance of Online Banking: A Focus on the Dimensions of Risk. Journal of Systems and Information Technology, 15(1), pp.97116.

Marakarkandy, B., Yajnik, N., and Dasgupta, C., 2017. Enabling Internet Banking Adoption: An Empirical Examination With an Augmented Technology Acceptance Model (TAM). Journal of Enterprise Information Management, 30(2), pp.263-294.

Massilamany, M. and Nadarajan, D., 2017. Factors That Influencing Adoption of Internet Banking in Malaysia. International Journal of Business and Management, 12(3), p.126.

Mukhtar, M., 2015. Perceptions of UK Based Customers toward Internet Banking in the United Kingdom. The Journal of Internet Banking and Commerce, 2015.

Oruç, Ö.E. and Tatar, Ç., 2017. An Investigation of Factors that Affect Internet Banking Usage Based on Structural Equation Modeling. Computers in Human Behavior, 66, pp.232-235.

Otoritas Jasa Keuangan. (2015). Bijak BereBanking.http://www.ojk.go.id/Files/201 509/BukuBijakBereBanking_144189091 3.pdf. (diunduh tanggal 10 Agustus 2016).

Riquelme, H.E. and Rios, R.E., 2010. The Moderating Effect of Gender in the Adoption of Mobile Banking. International Journal of bank marketing, 28(5), pp.328-341.

Shanmugam, M., Wang, Y.Y., Bugshan, H. and Hajli, N., 2015. Understanding Customer Perceptions of Internet Banking: The Case of the UK. Journal of Enterprise Information Management, 28(5), pp.622-636.

Sihotang, E.T., 2016. Faktor Penentu yang Mempengaruhi Penggunaan Layanan Internet Banking, Jurnal Ekonomi dan Manajemen, 13 (1), hal.25-36
Sihotang, E.T., 2016. Segmentasi Layanan Internet Banking, Jurnal Manajemen dan Kewirausahaan, 4 (2), hal.12-22.

Susanto, A., Lee, H., Zo, H. and Ciganek, A.P., 2013. User Acceptance of Internet Banking in Indonesia: Initial Trust Formation. Information Development, 29(4), pp.309-322.

Top Brand. (2017). Top Brand Award 2017, diunduh tanggal 31 Mei 2017 dari http://www.topbrand-award.com/topbrand-survey/surveyresult/top_brand_index_2017_fase_1.

Tseng, J.T., Han, H.L., Su, Y.H. and Fan, Y.W., 2017. The Influence of Intention to Use the Mobile Banking-The Privacy Mechanism Perspective. Journal of Management Research, 9(1), pp.117-137.

Venkatesh, V. and Bala, H., 2008. Technology Acceptance Model 3 and A Research Agenda on Interventions. Decision sciences, 39(2), pp.273-315.

Venkatesh, V. and Morris, M.G., 2000. Why Don't Men Ever Stop to Ask for Directions? Gender, Social Influence, and Their Role in Technology Acceptance and Usage Behavior. MIS quarterly, pp.115-139.

Yiu, C.S., Grant, K. and Edgar, D., 2007. Factors Affecting the Adoption of Internet Banking in Hong KongImplications for the Banking Sector. International Journal of Information Management, 27(5), pp.336-351.

Yousafzai, S. and Yani-de-Soriano, M., 2012. Understanding Customer-Specific Factors Underpinning Internet Banking Adoption. International Journal of Bank Marketing, 30(1), pp.60-81. 